\title{
Responsabilidad social de la empresa: ¿Ética, marketing o Derecho?
}

\author{
OSCAR ERMIDA URIARTE*
}

\begin{abstract}
SUMARIO: INTRODUCCIÓN.- I. ¿ÉTICA, MARKETING O DERECHO?- II. LA NATURALEZA JURÍDICA DE LOS CÓDIGOS DE CONDUCTA.- III. SU EFICACIA.IV. APROXIMACIÓN A LAS EXPERIENCIAS LATINOAMERICANAS.- V. ¿UNA REGULACIÓN INTERNACIONAL DE LA RSE?- VI. ALGUNAS BREVES CONCLUSIONES.
\end{abstract}

\section{INTRODUCCIÓN}

Una de las afirmaciones más frecuentes sobre la responsabilidad social de la empresa (RSE) es la de que se trataría de un concepto vago, impreciso, ambiguo o polisémico ${ }^{1}$. Generalmente entendida por parte de la doctrina - y especialmente en los ámbitos patronales_ como una decisión empresaria unilateral y voluntaria, de cumplimiento no obligatorio, que anuncia el propósito de observar determinado comportamiento en el área social —ante consumidores, medio ambiente, trabajadores, etcétera- ${ }^{2}$, ha sido definida por la Comisión Europea como «la integración voluntaria, por parte de las empresas, de las preocupaciones sociales y medioambientales en sus operaciones comerciales y sus relaciones con sus interlocutores» ${ }^{3}$.

En todo caso, desde el punto de vista del Derecho del trabajo, de ella nos interesa la denominada responsabilidad social «interna» o «laboral», que se refiere a la acción o actitud de la empresa ante sus trabajadores ${ }^{4}$.

Es catedrático de Derecho del Trabajo y de la Seguridad Social en la Facultad de Derecho de la Universidad de la República, en Uruguay. Fue profesor de Derecho Colectivo del Trabajo en la Facultad de Derecho de la PUCP. El texto que se presenta a continuación es una reelaboración actualizada del originalmente publicado en la revista Derecho Laboral, tomo L, № 226, 2007, pp. 307 y siguientes, Montevideo, bajo el título de «Responsabilidad social de la empresa: entre la mercadotecnia y el Derecho".

1 Por ejemplo, véase APARICIO TOVAR, Joaquín y Margarita BARAÑANO. "Concepto de responsabilidad social empresarial». Se trata de un documento de trabajo elaborado en el marco del proyecto europeo de investigación ESTER, desarrollado por el Consejo Nacional de la Investigación Científica (CNRS) y por el Centro de Derecho Comparado del Trabajo y de la Seguridad Social (COMPTRASEC) de la Universidad Montesquieu - Burdeos IV (Francia), con la participación de las universidades de Castilla-La Mancha y Complutense de Madrid (España), Libre de Bruselas (Bélgica) y las de Trento (Italia), Utrech (Holanda) y Essex (Inglaterra). Del mismo modo, véase MERINO SEGoviA, Amparo. «Responsabilidad social corporativa: su dimensión laboral». Es otro documento de trabajo del mismo proyecto, en este caso publicado, además, con variantes, en Documentación Laboral, № 75, 2006, Madrid. También APARICIO TOVAR y Berta VALDÉS DE LA VEGA. «Sobre el concepto de responsabilidad social de las empresas. Un análisis europeo comparado". Cuadernos de Relaciones Laborales, vol. 27, № 1, 2009, pp. 53 y siguientes, especialmente 59 y 63, Madrid.

2 GaRmendiA, Mario. Eficacia práctica de las normas laborales. Montevideo: Fundación de Cultura Universitaria, 2005, p. 51.

3 Comisión Europea. Libro Verde. Fomentar un marco europeo para la responsabilidad social de las empresas, 18.7.2001, COM/2001/0366 final, párrafo 20. En <http://eur-lex.europa.eu>.

4 Otro uso de la expresión "dimensión interna» de la RSE es la que la refiere a las acciones de la empresa respecto de su personal directo. Se denomina responsabilidad "externa" a la que se refiere a las acciones de los subcontratistas, concesionarios y proveedores. Véase, por ejemplo, MERINO SEGOVIA, Amparo. «Responsabilidad social corporativa...». Óp. cit., párrafos 3.1 y 3.2. 
Esta «responsabilidad social» se expresa, generalmente, a través de los denominados «códigos de conducta», definidos en el Libro Verde de la Unión Europea como una «declaración formal de los valores y prácticas comerciales de una empresa y, algunas veces, de su proveedores ${ }^{5}$, lo que plantea diferentes problemas, algunos de los cuales se enuncian en este artículo ${ }^{6}$.

No se tratan aquí, en cambio, otras modalidades y manifestaciones de la RSE — como el etiquetado social y la certificación, las inversiones socialmente responsables, el balance social, el plan social y los observatorios-, salvo en la medida en que se relacionan con o repercuten en los códigos de conducta. Tampoco se hará un análisis de los contenidos sustantivos de los referidos códigos.

\section{I. ¿ÉTICA, MARKETING O DERECHO?}

Antes que nada, una aclaración: nada en contra tenemos de la introducción o del destaque de las consideraciones éticas en el Derecho del trabajo y en las relaciones laborales. Por el contrario, nos hemos ocupado de ello ${ }^{7}$ y hemos hecho propuestas al respecto ${ }^{8}$. Claro está, sin embargo, que la introducción de la ética debe ser ética, valga la redundancia, es decir, transparente, honesta, sincera y no limitarse a una alegación tendiente a encubrir otras finalidades. Y esto es, precisamente, lo que está en debate respecto de la denominada responsabilidad social de la empresa.

Existen serias reticencias o sospechas en torno a la verdadera motivación de la adopción, por parte de las empresas, de estos códigos de conducta unilaterales. Parece evidente que la idea nace como una estrategia comercial de imagen y que ese continúa siendo su principal objetivo", sin perjuicio de lo cual es probable que el transcurso del tiempo — con las críticas formuladas, el desarrollo de estudios serios y el debate que se

5 Ibíd., anexo.

6 Con la importante excepción del contenido sustantivo o material de los códigos de conducta. Al respecto, pueden verse, entre otros: ORSE (Observatoire sur la Responsabilité Sociétale des Entreprises). «Répertoire sur les pratiques des entreprises en matière de négociation des accords-cadres internationaux», París, 2006, especialmente pp. 27 y siguientes; OIT, Consejo de Administración (GB). «Grupo de trabajo sobre las dimensiones sociales de la liberalización del comercio internacional», Ginebra, 1998, especialmente párrafos 46 a 59, pp. 24 a 35; y MERINO SEgoviA, Amparo. «La definición de las cualidades morales y éticas de los trabajadores de la empresa de dimensión transnacional: los códigos de comportamiento ético y profesional». Revista de Derecho Social, № 31, 2005, pp. 91-96, Albacete.

7 ERMIDA URIARTE, Oscar. «Ética y Derecho del trabajo». Grupo de los Miércoles. Veinte estudios laborales en memoria de Ricardo Mantero Álvarez. Montevideo, 2004, pp. 17 y siguientes.

8 ERMIDA URIARTE, Oscar. «Relaciones laborales: nuevas variables e indicadores». Judicatura, № 40, 1999, Montevideo; y X Encuentro Grupo Bologna/Castilla-La Mancha. «Trabajo decente». Montevideo, 2002, pp. 89 y siguientes.

9 De hecho, el mismo Libro Verde de la Comisión Europea reconoce expresamente que «la responsabilidad social puede tener un valor económico directo" (párrafo 11) y que las empresas la adoptan «especialmente para mejorar su imagen empresarial y reducir el riesgo de que los consumidores reaccionen negativamente» (párrafo 54). 
instalara- haya permitido sofisticar un poco su presentación y probablemente también su práctica ${ }^{10}$.

Desde el punto de vista jurídico, se ha criticado duramente el uso de la expresión «responsabilidad» en esta materia. Lo que hacen las empresas bajo el rótulo de «responsabilidad social» no sería responsabilidad sino filantropía o acción social ${ }^{11}$, en tanto se defiende su voluntariedad y no exigibilidad por terceros, especialmente por los beneficiarios de esa acción. Parece cierto que ningún jurista serio hablaría de una «responsabilidad voluntaria».

Estas dudas son a menudo reforzadas por la vaguedad con la que generalmente están redactados estos documentos, lo que obviamente dificulta su aplicabilidad ${ }^{12}$, a lo que se suma que, por lo general, los códigos de conducta son instrumentos elaborados «de arriba hacia abajo», cuando muchos opinan que lo ideal sería que fueran creados «desde abajo hacia arriba» ${ }^{13}$.

Por lo demás, es necesario tener en cuenta una constatación de la OIT ${ }^{14}$ : generalmente, los códigos de conducta de las empresas multinacionales son bien conocidos en los países sede y muy poco difundidos o derechamente desconocidos en los países de destino, en los cuales, a menudo, se realiza la mayor parte de la producción y donde, por lo tanto, sería más necesario y útil su conocimiento y aplicación.

Sin lugar a dudas, en la responsabilidad social de la empresa hay mucho de marketing, de campaña de imagen, de publicidad y de promoción. Lo que al jurista puede corresponderle es la determinación de qué hay de Derecho allí y cuánto Derecho se le puede arrancar a esa operación de mercadotecnia.

\section{II.LA NATURALEZA JURÍDICA DE LOS CÓDIGOS DE CONDUCTA}

El tema central — del cual se deriva, además, el que se desarrolla en el apartado siguiente- es el de si los códigos de conducta son normas

10 Sobre ello, puede valer la pena narrar una experiencia personal. Cuando hace unos cuantos años comencé a estudiar este tema, hice una búsqueda en Internet. Recurrí a Google y allí escribí «responsabilidad social empresa». Las primeras diez referencias eran todas, sin excepción, del siguiente tenor: «la ética es un buen negocio», "cómo ganar dinero con la responsabilidad social», etcétera. Era obvio, en ese momento al menos, el verdadero objetivo de esta práctica: mejorar la imagen de la firma para ganar más dinero o perder menos. En marzo de 2007 repetí aquella experiencia de años atrás, con diferente resultado. La primera referencia se titulaba, igual que antes: "La responsabilidad social de la empresa: un buen negocio»; sin embargo, las nueve referencias siguientes ya eran de un tenor más objetivo y parecían contener trabajos un poco más «científicos» u objetivos. En 2008, ya todas las primeras referencias eran de este otro tenor.

11 ACKERMAN, Mario. "Consideración jurídico laboral de la llamada responsabilidad social de la empresa». Relaciones Laborales, № 11, 2006, pp. 26 y 29-30, Montevideo.

12 Véase el punto III de este trabajo.

13 La intervención pertenece a Jaspers, T. (Universidad de Utrecht) y fue registrada durante el «Colloque de l'irresponsabilité a la responsabilité des entreprises transnacionales dans la globalisation de l'economie", Proyecto ESTER, Université Montesquieu (Bordeaux IV), el 28 de marzo de 2007.

14 OIT. Óp. cit., p. 35, párrafo 60. 
jurídicas o no. En otras palabras, si de ellos pueden derivarse derechos exigibles por los trabajadores o sus organizaciones.

Está claro que los códigos de conducta unilaterales y no vinculantes no son normas jurídicas tradicionales, dotadas de coerción y ejecutabilidad, pero se dice que forman parte de lo que se ha dado en denominar softlaw, algo así como «paranormas», «protonormas», «prenormas», «seudo normas» $\mathrm{O}$ «cuasi normas», recomendaciones, sugerencias, buenos propósitos o proyectos destinados no a imponer un determinado comportamiento, sino a sugerirlo ${ }^{15}$.

$\mathrm{Al}$ respecto, cabe hacer algunas consideraciones. En primer lugar, hay que llamar la atención sobre la mala o insuficiente difusión con la que a menudo cuenta el soft-law. Baste pensar, como ejemplo, en los repertorios de recomendaciones prácticas del Consejo de Administración de la OIT, muchos de ellos de excelentes contenidos pero casi desconocidos, al menos en la mayor parte de los países latinoamericanos.

Una segunda apreciación, esta de tono más optimista, es la que llama la atención sobre el papel creativo, germinal o propulsor que pueden tener algunas normas de soft-law. En efecto, a veces algunas de ellas logran inspirar la adopción de normas propiamente tales, vinculantes, o generar prácticas que se tornan obligatorias o que incluso devienen ellas mismas en normas obligatorias ${ }^{16}$. En todo caso, el pluralismo jurídico no es tan novedoso en la teoría general del Derecho ni en el Derecho del trabajo en particular. El monopolio estatal del Derecho es un dogma consolidado durante el siglo XIX que vino a ser quebrado en el siglo XX precisamente por el Derecho laboral, a través del convenio colectivo (fuente no estatal de Derecho), que tal vez haya surgido no como la norma jurídica plena que es hoy en la mayor parte del mundo, sino - tal vez- como una "palabra de honor» o «pacto de caballeros» (Inglaterra), o como un «armisticio» o «tratado de paz» (Suiza, Alemania). Por lo tanto, no se puede descartar de manera tajante, absoluta o definitiva que los códigos de conducta puedan llegar a ser —ni que eventualmente ya lo sean- una nueva fuente de Derecho ${ }^{17}$.

En tercer lugar, también se ha señalado que, aun cuando los códigos de conducta no llegaran a revestirse de coercibilidad, sí podrían ofrecer algún interés o utilidad, en la medida en que - y solo si- verdaderamente generaran un sentido de «responsabilidad social» en los principales de las empresas ${ }^{18}$, es decir, si consiguieran cambiar la cultura empresaria de irresponsabilidad, de inmunidad, de evasión. Claro que esto se parece

15 Sobre el concepto de soft-law, véase MERINO SEGoviA, Amparo. "Soft-law y globalización». En Estudios de teoría crítica de Derecho del trabajo (inspirados en Moisés Meik). Buenos Aires: Bomarzo Latinoamericana, 2006, pp. 165 y siguientes.

16 BARRETTO GHIONE, Hugo. «Derechos del trabajador en el orden jurídico de Babel: la norma laboral en tiempos de globalización, integración y libre comercio en América Latina». Revista de Derecho Social-Latinoamérica, № 2, 2007, pp. 38 y siguientes, Buenos Aires.

17 Véase el punto III, especialmente III.2 y III.3.

18 GARMENDIA, Mario. Óp. cit., pp. 55-56. 
mucho a una utopía - lo cual no sería grave - o a un engaño - lo que sí sería preocupante-. Todavía cabe agregar que también desde el terreno de la ética se han levantado voces contrarias a lo que consideran una reducción de la moral al Derecho ${ }^{19}$.

En cuarto término, es inevitable que en tiempos de desregulación y flexibilización salvaje, como los que se vienen en la mayor parte de los países latinoamericanos, la irrupción de la propuesta de responsabilidad social sea vista como la pretensión de las grandes empresas de sustituir la normatividad estatal — es decir, las normas jurídicas propiamente dichaspor sus propias «normas», lo cual generaría una suerte de «feudalismo industrial» ${ }^{20}$.

Finalmente, no son pocos quienes opinan que la primera y principal responsabilidad de la empresa es cumplir escrupulosamente la legislación en sentido amplio (normas estatales y convenios colectivos).

\section{SU EFICACIA}

Si no son normas jurídicas propiamente dichas, si más bien son normas éticas o propósitos — cuando no mera publicidad-, entonces no se puede hablar de una eficacia jurídica, en el sentido de la posibilidad de alcanzar su aplicación forzosa o una reparación por el incumplimiento. Sin embargo, ya se dijo que no deben minimizarse los efectos que estos códigos voluntarios podrían llegar a tener, sea como impulsores de normas futuras o como inductores de determinadas conductas, y corresponde agregar aquí que también pueden ser relevantes los mecanismos de evaluación, seguimiento o aplicación eventualmente previstos en los propios códigos de conducta ${ }^{21}$, aunque en general, cuando existen, estos mecanismos no están suficientemente desarrollados.

Por eso, desde el punto de vista jurídico, nos parece más interesante explorar el grado de eficacia jurídica propiamente dicha que los códigos

19 «Tampoco es conveniente reducir la moral al Derecho, como se intenta actualmente a través por ejemplo- de su liso y llano reemplazo por códigos de ética, de estructura cuasi-jurídica». ZAVADIVKER, Nicolás. «Derecho y moral». Relaciones, № 307, diciembre de 2009, p. 5, Montevideo.

$20 \mathrm{El}$ reiteradamente citado Libro Verde aclara que la RSE «no se debe considerar sustitutiva de la reglamentación o legislación sobre derechos sociales o medioambientales, ni permite tampoco soslayar la elaboración de nuevas normas apropiadas" (párrafo 22); del mismo modo, la doctrina es clara en admitir la RSE como complemento pero no como sustitución de la normativa «tradicional» (véase SERVAIS, Jean-Michel. "Normes internacionales du travail et responsabilité sociale des entreprises". En Les normes internacionales du travail: un patrimoine pour l'avenir. Melanges en l'honneur de Nicolas Valticos. Ginebra: OIT, 2004, p. 580). La propia OIT lo ha manifestado: las buenas prácticas recogidas en los códigos de conducta y, en general, en los diversos instrumentos de RSE «no pueden sustituir la legislación destinada a prevenir las prácticas inadecuadas y que permite la aplicación de sanciones» (OIT. «Cambios en el mundo del trabajo», memoria del director general a la 95 a Conferencia Internacional del Trabajo, 2006, p. 74, Ginebra). Y obviamente los sindicatos subrayan que la RSE no puede sustituir a las funciones del Estado, al enfatizar que «las empresas [...] no tienen ninguna legitimidad política» (RYDER, Guy. "La responsabilidad social de las empresas y los derechos de los trabajadores". Educación Obrera, № 130, 1/2003, OIT, 2003, p. 24, Ginebra). Sin embargo, es igualmente claro que en la práctica ese riesgo está muy presente (véase abajo, punto $\mathrm{V}$ ).

21 El Libro Verde destaca, al final de la definición de código de conducta, la importancia que tales mecanismos pueden tener (anexo).

RESPONSABILIDAD SOCIAL DE LA EMPRESA: ¿ÉTICA, MARKETING O DERECHO? 
de conducta puedan llegar a tener, sobre lo cual sería posible distinguir varias hipótesis o niveles.

\section{III.1. La interpretación del contrato de trabajo y de las actitudes del empleador}

En todo caso, aun cuando sea unilateral y no obligatorio, el código de conducta podrá ser utilizado para interpretar una cláusula del contrato de trabajo o las actitudes del empleador ${ }^{22}$. Es claro, en nuestra opinión, que aquel uso interpretativo del código de conducta unilateral solo puede manifestarse en el marco de las reglas hermenéuticas del Derecho del trabajo; esto es, solo podrá operar en favor del trabajador.

\section{III.2. La aplicación de cláusulas del código de conducta unilateral}

El código de conducta unilateral puede ser entendido como una manifestación de voluntad unilateral del empleador que «autolimita» sus facultades o atribuciones. En ese sentido, lo obliga — como en Uruguayel reglamento interno ${ }^{23}$, y el cumplimiento de sus cláusulas, en tanto más favorables que las contenidas en el contrato, el convenio colectivo o la ley, podría ser exigido por los trabajadores.

Por eso mismo, aquellos códigos de conducta o aquellas de sus cláusulas que intentan imponer obligaciones al trabajador o negarle o limitarle derechos $^{24}$ serán inevitablemente nulos e ineficaces desde el punto de vista jurídico ${ }^{25}$. Esta aclaración es importante, habida cuenta de la existencia de «códigos de conducta» dirigidos más al trabajador que al empleador, es decir, que pretenden fijar pautas de conducta no a la empresa sino a sus trabajadores. Está claro que estas pautas solo tendrán valor en tanto sean más favorables.

\section{III.3. La aplicación de las cláusulas bilaterales del código de conducta}

En cuanto recogido o negociado en un convenio colectivo, el código de conducta tendría la validez y la eficacia de tal, y por tanto podría ser

22 LÓPEZ, Diego. «Responsabilidad social empresarial: autorregulación empresarial en materia laboral». Revista Laboral Chilena, № 1/2007, 2007, p. 69, Santiago.

$23 \mathrm{El}$ reglamento interno es visto como una autolimitación de los poderes del empleador, que en tanto sea más favorable para el trabajador puede ser exigida por este (compárese, entre otros, LóPEZ, Diego. Óp. cit., p. 70).

24 Merino Segovia, Amparo. "La definición de las cualidades morales y éticas». Óp. cit., pp. 85 y siguientes. Para una clasificación de diferentes tipos de códigos de conducta, véase MERINO SEGOVIA, Amparo y Jesús RENTERO JOVER. «Formas atípicas de regulación de las relaciones laborales en la empresa transnacional: códigos de conducta y buenas prácticas». En Antonio Baylos Grau (coordinador). La dimensión europea y transnacional de la autonomía colectiva. Albacete: Editorial Bomarzo, 2004, pp. 274 y siguientes.

25 Sin perjuicio de ello podrán tener eficacia práctica, en cuanto sin duda ejercerán presión sobre el trabajador. 
exigido por el sindicato co-celebrante ${ }^{26} \mathrm{y}$, en nuestra opinión, también por los trabajadores alcanzados o cubiertos por el referido convenio, habida cuenta del denominado efecto normativo del convenio colectivo, admitido en la mayor parte de los países latinoamericanos.

En todo estos $\operatorname{casos}^{27}$, la frecuente vaguedad de las cláusulas de los códigos de conducta (arriba señalada) dificulta su eficacia.

\section{III.4. Competencia y legislación aplicable en caso de có- digos de conducta de empresas multinacionales}

Llegados a este punto, en el caso de las empresas multinacionales irrumpe la ardua cuestión de determinar la ley aplicable y la jurisdicción competente según la cual y ante la cual accionar para obtener la ejecución de una cláusula del código de conducta.

Dentro de los innumerables problemas que se plantean, uno de los más interesantes es el de la posibilidad de que el sindicato o los trabajadores del país de destino accionen la ejecutabilidad del código de conducta de la empresa matriz ante la justicia del país sede ${ }^{28}$. Sin perjuicio de ello, en nuestra opinión, los trabajadores de la filial de una multinacional pueden también demandar la aplicación del código de conducta en su propio país, no solamente cuando el referido código haya sido adoptado localmente, sino aun cuando no lo haya sido, en aplicación del concepto de unidad de la empresa multinacional y sus consecuencias ${ }^{29}$.

\section{III.5. La búsqueda alternativa de la eficacia}

El carácter todavía embrionario de las construcciones tendentes a arrancar la máxima eficacia posible de los códigos de conducta —o de reducir su vocacional ineficacia - ha llevado a la búsqueda de fuentes alternativas de eficacia. Además de las más conocidas certificaciones de tipo ISO (International Organization for Standardization) y del etiquetado social, nos interesa señalar aquí dos experiencias latinoamericanas de cierto interés:

1. El control sindical de la observancia del código, todavía unilateral. Es el caso del observatorio social de la central brasileña CUT, que realiza un seguimiento del comportamiento de determinadas empresas multinacionales que adoptaron códigos de conducta unilaterales. Las pesquisas se realizan, según el caso, con o sin el consentimiento de la empresa, y derivan en la publicación de los resultados.

26 BAylos Grau, Antonio. «La responsabilidad legal de las empresas transnacionales». Revista de Derecho Social Latinoamérica, № 1, 2006, pp. 98-99, Buenos Aires.

27 Véanse los puntos III.1. a III.3.

28 Al respecto, véase BAYLOS GRAU, Antonio. «La responsabilidad legal...». Óp. cit., pp. 93 y siguientes.

29 ERMIDA URIARTE, Oscar. Empresas multinacionales y Derecho laboral. Montevideo: Amalio M. Fernández, 1981, pp. 87 y siguientes, y 133 y siguientes. También véase, aunque sin referencia específica a las multinacionales, CASTELLO, Alejandro. Grupo de empresas y Derecho del trabajo. Montevideo: Fundación de Cultura Universitaria, 2006. 
2. La premiación estatal de las buenas prácticas. Es el caso del Plan Nacional de Fomento del Trabajo Decente y la Competitividad Empresarial, elaborado por el Ministerio de Trabajo del Perú y aprobado por la resolución ministerial 181-TR de 2004, que lamentablemente no ha llegado a ponerse en práctica a pesar de haber sido cuidadosamente elaborado. De conformidad con dicho plan, el Estado ofrecería determinadas ventajas a las empresas que voluntariamente se avinieran a cumplir con ciertas metas u objetivos laborales. Había un primer nivel de buenas prácticas, que era el del cumplimiento estricto de la legislación vigente, controlado por la Inspección del Trabajo. Un segundo nivel, más alto, se reconocería, con ventajas adicionales, a las empresas que acreditaran ante el Ministerio de Trabajo la concesión de determinados beneficios adicionales a los legales, como formación profesional, promoción de la libertad sindical y de la negociación colectiva, entre otros ${ }^{30}$.

\section{III.6. La regulación legal de la RSE}

La búsqueda de la eficacia desemboca en la propuesta de regulación legal ${ }^{31}$ : los códigos de conducta devendrían, así, en soft-law convertido en hard-law o regulado por este.

Es que, como se dijo en el Coloquio de Burdeos de marzo de $2007^{32}$, a pesar de la «vulgata» neoliberal sobre la presunta inutilidad de las normas, la evidencia objetiva señala, en cambio, la necesidad de las normas y, más aún, su inevitabilidad. En efecto, cuando no las hay, los actores las crean (autonomía) ${ }^{33}$ o «juegan a las reglas» y en consecuencia las simulan, como sucede, a veces, con la RSE, los códigos de conducta, etcétera. Se juega al Derecho, teatralizándolo, y representando el papel del legislador. Jugar al Derecho puede ser, claro está, una forma de sublimarlo, de reprimirlo, de evitarlo en la vida real.

Más aún, la necesidad de la normatividad hace que, cuando ella no es posible, se la invente y se la venda: surgen así los denominados «códigos tipo» y la comercialización de certificaciones, acreditaciones o «diplomas». Esta es, precisamente, una de las manifestaciones de lo que Umberto Romagnoli gusta denominar «el mercado de las reglas» ${ }^{34}$.

30 Una breve referencia a dicho plan puede verse en MORILLO SANTA CRUZ, Laura Raquel. «La responsabilidad social empresarial en el ámbito laboral». Laborem, № 5, 2005, pp. 395-397, Lima.

31 «Legal», aquí, en sentido amplio: regulación por una norma jurídica plena, propiamente dicha, coercible.

32 Exposición verbal de T. Cochoy, sociólogo de la Universidad de Toulouse II, recogida el 30 de marzo de 2007.

33 Una de las causas - que no la única- del surgimiento de la RSE sería el debilitamiento del papel regulador del Estado (SERVAIS, Jean-Michel. Óp. cit., p. 565).

34 Otra de las manifestaciones de este mercado de las reglas al que lleva la exacerbación de las reglas del mercado se manifiesta cuando las empresas multinacionales "escogen» el orden jurídico más favorable (para ellas) al instalar sus establecimientos y (peor) cuando los Estados nacionales se anticipan y rebajan sus estándares para competir entre sí, en un intento por lucir más seductores ante el inversionista externo. 
Una regulación real puede ser alcanzada a través de la autonomía colectiva, como ya fue dicho, o derechamente dictada por el Estado. Algunos países ${ }^{35}$ cuentan ya con una ley sobre la responsabilidad social de la empresa y otros ${ }^{36}$ se encuentran en la etapa de estudio y eventual elaboración de una norma de aquel tipo.

\section{III.7. La regulación internacional de la RSE (remisión)}

El contexto de la globalización, las dificultades de los ordenamientos jurídicos nacionales para regularla y la circunstancia de que las principales protagonistas de los códigos de conducta sean las empresas multinacionales traen naturalmente al debate la posibilidad de proceder a una reglamentación internacional. A ella nos referiremos más adelante ${ }^{37}$.

\section{V. APROXIMACIÓN A LAS EXPERIENCIAS LATINOAMERICANAS}

No es fácil formular un juicio único común sobre la recepción y la eficacia de los códigos de conducta de las empresas multinacionales en Latinoamérica, entre otras razones, por las diferencias que existen entre los diversos países y por las igualmente existentes entre las mismas transnacionales.

En relación con las diferencias entre las diversas empresas multinacionales en función de su origen o país sede, tenemos la impresión de que existe una expectativa de que las transnacionales europeas observen un comportamiento «socialmente correcto» y superior al de las de origen estadounidense ${ }^{38}$. Sin embargo, no está claro que esa expectativa se refleje en la realidad. En todo caso, creemos que puede decirse que ella no siempre se ve realizada.

Hasta el momento es probable que, en la práctica, haya influido algo más el contexto del lugar de destino. La «corrección social» del comportamiento de las empresas transnacionales parece influido, al menos en parte, por la acción del Estado y los sindicatos del país de acogida. El caso más demostrativo se observa en las zonas francas o «maquilas»

35 Como Bélgica, Francia y Holanda.

36 Como España.

37 Véase el punto $\mathrm{V}$

38 Más aún, la Comunicación de la Comisión Europea al Parlamento Europeo, al Consejo y al Comité Económico y Social Europeo de 2006 (COM/2006/0136 final) se titula «Poner en práctica la asociación para el crecimiento y el empleo: hacer de Europa un polo de excelencia de la responsabilidad social de las empresas» e insiste en que la responsabilidad social empresaria forma parte del «modelo social europeo» o «modelo europeo de sociedad», el que se basa "en la igualdad de oportunidades, una gran calidad de vida, la inclusión social y un medio ambiente sano» (párrafos 1, 2 y 6). Agrega, asimismo, que en función de ello "las empresas europeas deberían actuar con responsabilidad dondequiera que operen, con arreglo a los valores europeos y a las normas internacionalmente aceptadas» (párrafo 3) y «sobre todo en los países en vías de desarrollo» (párrafo 2). Finalmente, en el anexo se acentúa que la RSE «es importante para la gente de otras partes del mundo, que espera que las empresas situadas en Europa actúen de conformidad con los valores y principios europeos e internacionales», por lo cual las empresas europeas deberían operar "más allá de las fronteras de la Unión Europea de la misma manera social y ambientalmente responsable que dentro de la Unión Europea».

RESPONSABILIDAD SOCIAL DE LA EMPRESA: ¿ÉTICA, MARKETING O DERECHO? 
— existentes especialmente en Centroamérica y México—, en las cuales el Estado concede franquicias a la inversión extranjera directa, las que a veces incluyen «franquicias laborales» que, cuando se registran, no dejan de ser aprovechadas. Debe aclararse, sin embargo, que en estas «maquilas» o zonas francas es mucho mayor la presencia de multinacionales estadounidenses que europeas.

Estos casos de «paraísos laborales» ejemplifican muy bien el riesgo, también mencionado ya ${ }^{39}$, de que las multinacionales tiendan a generar, en su entorno, una suerte de «feudalismo industrial» y jurídico, en el cual la autorregulación a través de los códigos de conducta podría, eventualmente, llegar a sustituir el Derecho estatal nacional. Este riesgo no deja de ser preocupante, en momentos en que se avizora una suerte de «reregulación» del Derecho del trabajo en algunos países latinoamericanos $^{40}$, proceso que podría encontrar en estos espacios de autorregulación patronal uno de los escollos a superar.

Puede ejemplificar este conflicto el caso de la histórica sentencia del Tribunal Constitucional peruano, que dispusiera la reinstalación de cientos de trabajadores despedidos por una multinacional española de las telecomunicaciones. Aquel fallo inauguró una importante jurisprudencia de aplicación directa de derechos laborales de rango constitucional e internacional, aun en contra de normas legales expresas ${ }^{41}$.

Otra situación que debe ser destacada es la responsabilidad de las empresas multinacionales en el uso desmedido de la subcontratación y de otras formas de tercerización. Cabe precisar que en esto han jugado un papel determinante las directivas de ajuste y rendimiento fijadas por la casa matriz a las filiales. Cuando el responsable de una filial recibe la indicación de que debe obtener ciertos resultados con determinada plantilla —real o subjetivamente insuficiente-, el recurso a la «externalización» es la salida que permite al gerente local cumplir —al menos formalmente- con las metas fijadas. Obsérvese la frecuencia con que la reducción de personal es acompañada por la consecutiva subcontratación de trabajadores - a veces, de los mismos que fueran despedidos_ ${ }^{42}$.

Asimismo, no deja de resultar paradójico que, habiendo sido uno de los principales agentes de la subcontratación y tercerización, la multinacional también se erija en su aparente corrector e incluya en sus códigos de conducta pautas de comportamiento para sus subcontratistas e intermediarios ${ }^{43}$.

39 Véase arriba, punto II.

40 ERMIDA URIARTE, Oscar. «Caracteres y tendencias del Derecho del trabajo en América Latina y en Europa». Revista de Derecho Social-Latinoamérica, № 1, 2006, pp. 7 y siguientes, Buenos Aires.

41 Tendencias análogas pueden percibirse en el Tribunal Constitucional de Colombia y en las Cortes Supremas de Argentina y Costa Rica.

42 Sobre el proceso de descentralización empresaria en general, véase ERMIDA URIARTE, Oscar y Natalia Colotuzzo. Descentralización, tercerización, subcontratación. Montevideo: OIT, 2009.

43 Los documentos de la Comisión Europea de 2001 y 2006 ya citados aquí se refieren reiteradamente a esta cuestión, lo mismo que la Resolución del Parlamento Europeo del 13 de marzo de 2007 (punto III). También debe registrarse la Propuesta de Resolución del Parlamento Europeo de 2008 sobre la 


\section{V. ¿UNA REGULACIÓN INTERNACIONAL DE LA RSE?}

Como se adelantón ${ }^{44}$, varias circunstancias llevaron a que inevitablemente se planteara la posibilidad de proceder a una reglamentación internacional de la RSE: el contexto de la globalización y las dificultades de los ordenamientos jurídicos nacionales para regularla —incluida la insatisfacción con sus escasos niveles de eficacia-, la circunstancia de que los principales protagonistas de los códigos de conducta sean las empresas multinacionales, entre otros. A estos motivos se sumaron los dos fundamentales y generales que han animado toda reglamentación laboral, nacional e internacional a lo largo de la historia del Derecho del trabajo: en primerísimo plano, la protección del trabajador y, en un segundo nivel, la organización de la producción a través de la regulación de la competencia, para evitar que esta se desarrolle sobre la base de la imposición de malas condiciones de trabajo. En este último plano, así como el empleador que cumple rigurosamente sus obligaciones laborales tiene la legítima expectativa de que sus competidores también lo hagan, puede presumirse que el empresario que va más allá y asume compromisos sociales mayores también alienta alguna expectativa de no verse perjudicado y, más aún, de que los estándares de buenas prácticas que pueden manejar sus competidores sean realmente tales y no meras fachadas diseñadas a la medida de los intereses de cada uno.

\section{V.1. Enumeración}

Si bien no existe, por el momento, una reglamentación internacional general y propiamente dicha de la responsabilidad social de la empresa, sí pueden observarse diversos antecedentes, múltiples tentativas o proyectos, y algunas pocas realizaciones concretas, de ámbito reducido al sector o rama de actividad o a la empresa transnacional ${ }^{45}$.

\section{V.1.1. Antecedentes}

Desde la década de 1970, en el seno de la ONU se analizó la viabilidad de una reglamentación del accionar de las empresas multinacionales por

responsabilidad social de empresas de subcontratación en cadenas de producción. La certificación RS 8000 sobre condiciones de trabajo, de SAI (Social Accountability International, entidad privada de los Estados Unidos de Norteamérica), extiende sus estándares laborales a toda la cadena de proveedores y contratistas de la empresa. En Uruguay, como en varios países latinoamericanos, se han aprobado, más o menos recientemente, leyes que disponen la responsabilidad — solidaria o subsidiaria, según los casos- de todo patrono o empresario que utilice subcontratistas, intermediarios o suministradores, lo que ha sido visto como una reacción ante el uso excesivo de estas figuras (véase ERMIDA URIARTE, Oscar y Natalia Colotuzzo, óp. cit.).

44 Véase arriba, punto III.7. Sobre este tema, entre otros autores, puede consultarse con provecho a DAUGAREILH, Isabelle. «Responsabilidad social de las empresas transnacionales: análisis crítico y prospectiva jurídica». Cuadernos de Relaciones Laborales. Óp. cit., pp. 77 y siguientes.

45 Entre otros, véase MERINO SEgOVIA, Amparo. «Mecanismos de regulación de la responsabilidad social de las empresas europeas». En La negociación colectiva europea. Manuales de Formación Continuada № 36. Madrid: Consejo General del Poder Judicial, 2006, pp. 339 y siguientes, especialmente 347 y siguientes; CARDEBAT, Jean-Marie. «Les normes sociales: nouvelle mode ou nouvelle régulation sociale?». Ecoflash, № 212, 2006, pp. 2-3, París; SERVAIS, Jean-Michel. Óp. cit., pp. 570 y siguientes; LÓPEZ, Diego. Óp. cit., pp. 67-68. Para detallada enumeración y análisis de los códigos de conducta negociados colectivamente, véase ORSE. Óp. cit., nota 6.

RESPONSABILIDAD SOCIAL DE LA EMPRESA: ¿ÉTICA, MARKETING O DERECHO? 
la vía de un código de conducta ${ }^{46}$. Las primeras concreciones al respecto se registraron, primero, en el seno de la OCDE, a través de sus «Guidelines» para las empresas transnacionales de 1976, y casi inmediatamente, en 1977, en la OIT, con la adopción de la Declaración Tripartita de Principios sobre las Empresas Multinacionales. Ambos instrumentos fueron actualizados en 2000, y en ese mismo año se aprobó el Pacto Global de la ONU, una especie de compromiso de empresas multinacionales, organizaciones no gubernamentales y sindicales para poner en práctica diez principios fundamentales extraídos de las Declaración Universal de Derechos humanos, de la Declaración de la OIT sobre Principios y Derechos Fundamentales en el Trabajo y de la Declaración de Río sobre Medio Ambiente ${ }^{47}$.

Por su parte, la Unión Europea viene discutiendo la posibilidad de una regulación regional específica de la responsabilidad social de las empresas europeas, a cuyo respecto pueden mencionarse los documentos ya citados $^{48}$ : el Libro Verde de 2001, la comunicación de 2006 y la resolución del parlamento europeo de 2007.

Paralelamente, deben registrarse las iniciativas sociales (convenios colectivos y acuerdos marco) y privadas, del tipo ISO, a las que se alude de inmediato.

\section{V.1.2. Las propuestas actuales}

Las iniciativas de regulación internacional de la RSE más activas en este momento son las emanadas del sector empresarial y privado, las provenientes de la autonomía colectiva y las propias de la Unión Europea.

Entre las iniciativas privadas, la más difundida es la de ISO, organización internacional privada de Derecho suizo que elabora «normas» pretendidamente universales, voluntarias y generalmente certificables en diversas temáticas, predominantemente de interés empresarial. Actualmente, elabora una Guía ISO 26.000 sobre Responsabilidad Social, cuya puesta en funcionamiento está prevista para fines de 2010. Se trataría de una norma de vocación universal, voluntaria y, en este caso, a diferencia de la mayoría de las normas ISO, no certificable, a pedido del sector empleador y con la conformidad de los representantes sindicales participantes. Se tratará, aparentemente, solo de recomendaciones, pautas o sugerencias ${ }^{49}$ que enunciarían expectativas redactadas en condicional, las que propondrían el cumplimiento de la legislación nacional y de algunas normas internacionales - a diferencia de lo previsto en el Libro 
Verde de la Unión Europea, que considera que la RSE necesariamente debe significar un plus respecto de la legislación-.

Así, para muchos, el proyecto ISO 26.000 ingresaría a lo social en competencia con el sistema normativo de la OIT. Si a muchos preocupa que la RSE tienda a sustituir el Derecho estatal nacional, otros tantos se preguntan si el proyecto ISO 26.000 no operaría como un eventual sustituto del Derecho internacional del trabajo. El futuro dirá, respecto de ISO 26000, si «la montaña habrá parido un ratón» o si se trataba de un «caballo de Troya ${ }^{50}$.

Por lo demás, estamos aquí en el pleno terreno del ya mencionado «mercado de la reglas ${ }^{51}$, espacio de competencia comercial que se presta a la confusión por el uso de denominaciones que no facilitan la diferenciación. ISO no posee, por ahora, una norma de responsabilidad social, aunque a menudo se le atribuye la norma SA 8000 , que en verdad pertenece a otra institución: una empresa privada estadounidense denominada SAI (Social Accountability Internacional).

Entre las instituciones privadas que se dedican a la RSE, parece despertar mayor interés la francesa ORSE (Observatoire sur la Responsabilité Sociétale des Entreprises). De composición tripartita, no pretende elaborar normas pero sí promover la RSE a través del diálogo entre los actores sociales, la realización de estudios e investigaciones y la difusión de experiencias exitosas.

En verdad, las únicas reglamentaciones internacionales ya existentes en RSE que han superado el nivel del proyecto son las emanadas de la autonomía colectiva: los acuerdos globales o códigos de conducta negociados colectivamente. La ORSE registra numerosos acuerdos globales de empresas multinacionales, de los cuales una abrumadora mayoría corresponde a empresas europeas ${ }^{52}$, pero también existen varios acuerdos mundiales o europeos de rama o sector.

Finalmente, la Unión Europea debate, desde hace años, la adopción de una norma internacional sobre RSE. El origen del debate puede ubicarse en el denominado Libro Blanco sobre el crecimiento y el empleo de 1993. Luego, los reiteradamente citados Libro Verde de 2001, Comunicación de la Comisión de 2006 y Resolución del Parlamento Europeo de 2007 plantearon y desarrollaron la cuestión ${ }^{53}$. Puede decirse que hay algunos conceptos que pueden considerarse «adquiridos», tales como las ideas de que la RSE debe significar un plus sobre las obligaciones impuestas por las normas legales y los convenios colectivos, que debe incluir el reconocimiento de determinados principios y normas internacionales y

RESPONSABILIDAD SOCIAL DE LA EMPRESA: ¿ÉTICA, MARKETING O DERECHO? 
suponer la participación activa de los involucrados. Pero sigue pendiente la decisión de adoptar o no una reglamentación, así como de concederle carácter de voluntaria o de obligatoria ${ }^{54}$.

En todo caso, parece interesante la posición sustentada por la Confederación Europea de Sindicatos, de conformidad con la cual las empresas europeas pueden hacer RSE o no. Pero si deciden hacerla, deben hacerla de un modo serio, de acuerdo con un marco que debe existir.

\section{V.2. Sistematizaciones}

La doctrina ofrece diversas sistematizaciones de las formas de reglamentación internacional de la RSE, sin perjuicio de lo cual es posible intentar la formulación de otras.

Una primera sistematización y tal vez la de más amplio espectro sería la que tendría en cuenta el ámbito geográfico de la reglamentación existente o propuesta. Así se distinguirían, por una parte, las reglamentaciones de ámbito universal (como el Pacto Global de la ONU, la Declaración Tripartita de la OIT sobre Empresas Multinacionales, los acuerdos marco globales, tanto los sectoriales - que abarcan a todo un sector- como los códigos de conducta negociados en un acuerdo global de una empresa multinacional). Las ISO podrían inscribirse en este sector de normas con pretensión de alcance mundial, aunque su carácter privado torna muy discutible su inclusión junto con normas del Derecho internacional público y con productos de la autonomía colectiva internacional, como enseguida se indicará. Por otra parte se ubicarían las normas internacionales regionales, como las que podría emitir la Unión Europea u otro bloque regional.

La dificultad de englobar en una misma categoría a normas privadas y públicas alienta la formulación de una segunda sistematización, que precisamente distingue las diversas reglamentaciones internacionales existentes o propuestas en función de su fuente, pública o privada. De conformidad con este criterio, serían normas reglamentarias de la RSE de fuente pública las emanadas de la ONU, de la OIT y las que pudiera dictar la Unión Europea u otro bloque regional análogo, mientras que lo serían de fuente privada las emitidas por instituciones como ISO y SAI, las derivadas de la negociación colectiva y aun los códigos de conducta unilaterales, si se les atribuyera la condición de norma jurídica ${ }^{55}$.

Con análoga preocupación, una tercera sistematización ${ }^{56}$ distingue los que denomina «códigos tipo» de los que llama «códigos operativos». Los pri-

54 Algunos denuncian una falsa oposición entre voluntariedad y obligatoriedad o, por lo menos, la minimizan: es común, en el Derecho internacional, que el ingreso a un determinado sistema normativo sea voluntario - por ejemplo, la ratificación de un tratado-, pero, una vez producido el ingreso voluntario, el sistema obliga y vincula.

55 Puede discutirse la categorización de los códigos de conducta negociados colectivamente como de fuente privada. Podría sostenerse que son de Derecho social, si se sustenta la tesis de que sus normas constituyen un tertium genus entre lo público y lo privado.

56 SERVAIS, Jean-Michel. Óp. cit., pp. 567-570. 
meros serían estándares fijados por un tercero (público o privado), al cual deberían ajustarse las empresas. Los segundos serían elaborados por los propios interesados. La Declaración de Principios sobre las Empresas Multinacionales de la OIT, las recomendaciones de la OCDE, tanto como las normas tipo ISO, pertenecerían a la primera categoría. A la segunda pertenecerían los códigos de conducta unilaterales o aun los negociados colectivamente por las empresas ${ }^{57}$.

Una cuarta sistematización es la que puede realizarse en función del contenido de los instrumentos de RSE, sesgo no abordado en este estudio ${ }^{58}$. Sin embargo, conviene dejar indicado que desde tal punto de vista pueden distinguirse contenidos extensos o limitados —en cuanto al elenco de derechos reconocidos y de obligaciones o compromisos asumidos- - y contenidos más o menos importantes desde el punto de vista cualitativo. También pueden distinguirse los instrumentos de RSE según incluyan mecanismos de control o seguimiento, o carezcan de ellos. Del mismo modo, los instrumentos privados, especialmente, pueden distinguirse según cuenten con mecanismos de certificación o no.

Una quinta y última sistematización tiene en cuenta la eficacia jurídica de los instrumentos de RSE. Por supuesto que ello depende, en primer lugar, de la naturaleza de la norma (hard o soft), lo que constituye una primera distinción. Pero también depende de la redacción de las cláusulas, que pueden ser obligacionales o normativas, y que pueden estar redactadas de manera vaga o precisa. Asimismo, la pretensión de eficacia permite distinguir los instrumentos en estudio según contengan, como ya se dijo, mecanismos de control o seguimiento, o carezcan de ellos.

\section{ALGUNAS BREVES CONCLUSIONES}

Como quiera que la responsabilidad social de la empresa tiene un fuerte contenido - y tal vez un origen - mercadotécnico, la labor del jurista debe ser la de encontrar qué de jurídico hay en ella.

1. Desde el punto de vista jurídico, el aspecto más relevante del estudio de los códigos de conducta es el de su eficacia o exigibilidad.

a. En la medida en que contenga disposiciones más favorables para el trabajador que las establecidas por la ley, el convenio colectivo o el contrato individual de trabajo, el código de conducta podría ser considerado como un acto unilateral de autolimitación de facultades y atribuciones del empleador y, como tal, podría ser exigible por el trabajador. 
b. Las cláusulas de los códigos de conducta pactados en convenios colectivos deberían ser exigibles como cualquier norma de un convenio colectivo, tanto por el sindicato co-celebrante como por el trabajador incluido en el ámbito de aplicación del convenio.

c. Los códigos de conducta de las empresas multinacionales - a los cuales se les aplican íntegramente las conclusiones que anteceden - plantean otras cuestiones adicionales, como las relacionadas con la determinación de la ley aplicable y la jurisdicción competente.

2. En la práctica, los códigos de conducta de las empresas multinacionales son, a menudo, poco conocidos y poco aplicados en los países latinoamericanos de destino.

3. Las empresas multinacionales europeas tienden a desarrollar, en los países de destino, estándares de conducta laboral inferiores a los practicados en los países de origen. Es probable que el desarrollo del concepto de responsabilidad social de la empresa y de los códigos de conducta pueda contribuir modestamente a mejorar esa situación, pero, sin lugar a dudas, los verdaderos contrapoderes radican en la acción sindical (nacional e internacional) y en el papel del Estado, sin perjuicio de los esfuerzos de los organismos internacionales eventualmente competentes y de la procedencia de una eventual regulación internacional. 